
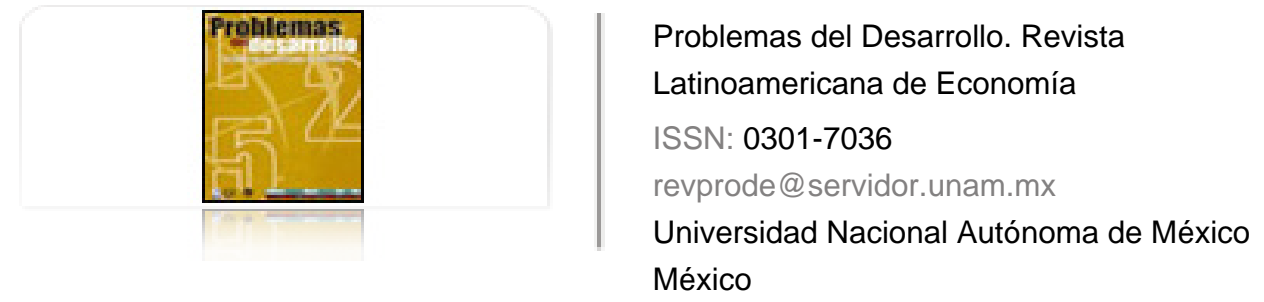

Huesca Reynoso, Luis; Rodríguez Pérez, Reyna Elizabeth Salarios y calificación laboral en México

Problemas del Desarrollo. Revista Latinoamericana de Economía, vol. 39, núm. 154, julio-septiembre, 2008, pp. 61-86

Universidad Nacional Autónoma de México

Distrito Federal, México

Disponible en: http://www.redalyc.org/articulo.oa?id=11820139004

Cómo citar el artículo

- Número completo

- Más información del artículo

- Página de la revista en redalyc.org

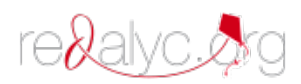

Sistema de Información Científica Red de Revistas Científicas de América Latina, el Caribe, España y Portugal Proyecto académico sin fines de lucro, desarrollado bajo la iniciativa de acceso abierto 


\title{
SALARIOS Y CALIFICACIÓN LABORAL EN MÉXICO
}

\author{
Luis Huesca Reynoso* \\ Reyna Elizabeth Rodríguez Pérez**
}

Fecha de recepción: 28 de enero de 2008. Fecha de aceptación: 3 de julio de 2008.

\section{Resumen}

Esta investigación muestra un análisis de los salarios en el mercado laboral de las regiones en México por trabajo calificado y no calificado entre los años 2000 y 2004. Los resultados se sustentan con la técnica no paramétrica de Jenkins y Van Kerm (2004). El ejercicio permite visualizar la distribución completa de los salarios de acuerdo con la descomposición de los subgrupos regionales en el país. Se determina que si bien el trabajo calificado percibe mayores remuneraciones que su contraparte, su estructura presenta mayor dispersión. La evidencia muestra una reducción en los niveles de concentración de los salarios entre el país y la frontera norte, mientras que las regiones del sur y centro observan cambios extremadamente reducidos. Se observa un incremento de la inequidad al interior del grupo calificado, debido al aumento en la heterogeneidad de los salarios dentro de este colectivo.

Palabras clave: salarios, distribución, trabajo calificado y no calificado, regiones.

* Investigador titular del Centro de Investigación en Alimentación y Desarrollo (CIAD). Correo electrónico: 1huesca@ciad.mx.

** Estudiante del doctorado en Ciencias de CIAD, Coordinación de Desarrollo Regional. Correo electrónico: reyna@estudiantes.ciad.mx. 
Abstract

This investigation analyzes wages in the labor market in Mexico's regions for skilled and unskilled labor between the years 2000 and 2004. The results are based on the nonparametric technique of Jenkins and Van Kerm (2004). The exercise makes it possible to visualize the entire distribution of wages according to a breakdown of the country's regional sub-groups. It is determined that while skilled labor earns higher remunerations than its counterpart, they show a very dispersed structure. The evidence shows a reduction in the levels of concentration for wages in the country and the northern border zone, while the southern and central regions show extremely small changes. An increase is seen in the inequality within the skilled group, due to a rise in the heterogeneity of wages within this section.

Key words: wages, distribution, skilled and unskilled labor, regions.

\section{Résumé}

Cette recherche montre une analyse des salaires sur le marché du travail des régions du Mexique pour les emplois qualifiés et les emplois sans qualification entre les années 2000 et 2004. Les résultats sont sustentés par la technique non paramétrique de Jenkins et Van Kerm (2004). Cet exercice permet d'obsever la distribution complète des salaires selon la décomposition en sous-groupes régionaux. Il est mis en évidence que les emplois qualifiés, s'ils perçoivent bien des rémunérations plus élevées, présentent une plus grande disparité. L'examen montre une réduction des niveaux de concentration des salaires si on monte vers la frontière nord, alors que les régions du sud et du centre observent très peu de changement. On constate un accroissement de l'iniquité à l'intérieur de la catégorie des travailleurs qualifiés qui patissent d'une plus grande hétérogénéité des salaires.

Mots clés: salaires, distribution, emplois qualifiés et non qualifiés, régions.

\section{Resumo}

Esta investigação mostra uma análise dos salários no mercado laboral das regiões no México por trabalho qualificado entre os anos 2000 e 2004. Os resultados sustentamse pela técnica não paramétrica de Jenkins e Van Kerm (2004). O exercício permite visualizar a distribuição completa dos salários de acordo com a decomposição dos subgrupos regionais no país. Determina-se que se bem o trabalho qualificado percebe maiores remunerações que sua contraparte, sua estrutura apresenta maior dispersão. A evidência mostra uma redução nos níveis de concentração dos salários entre o país e a fronteira norte, enquanto as regiões do sul e centro observam mudanças extremamente reduzidas. Observa-se um incremento da ineqüidade ao interior do grupo qualificado, devido ao acréscimo na heterogeneidade dos salários dentro deste coletivo.

Palavras chaves: salários, distribuição, trabalho qualificado e não qualificado, regiões. 


\section{Introducción}

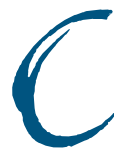

on la apertura comercial y la creciente competitividad entre las economías del mundo, el trabajo calificado ha tomado gran importancia en las décadas recientes, a tal grado de que el cambio tecnológico actual ha llegado a ser complementario y no sustitutivo de este tipo de labor, a diferencia de otro momento económico tal como la primera revolución industrial, donde el citado proceso sí sustituyó la mano de obra calificada (Acemoglu, 2002). Las agendas de los gobiernos y las empresas observan cada vez con mayor preocupación la inversión en capital humano, así como en investigación y desarrollo (I+D); es por ello que los países en el mundo global apuestan sus recursos hacia la inversión en capital humano como factor que impulsará el crecimiento y el desarrollo de las naciones. Es por ello que las firmas más productivas requieren de trabajadores con mayor educación para realizar labores con cada vez más valor agregado.

Si bien, la evidencia internacional reciente muestra que el cambio tecnológico afecta de manera positiva los salarios de las personas más calificadas en detrimento de los menos calificadas (Katz y Murphy 1991, Berman, et al., 1993 y 1997, Dunne, et al., 2000, y Acemoglu, 2001), la intención en este estudio no es profundizar sobre el cambio tecnológico, sino inferir las nuevas tendencias de los salarios vinculados con los grupos de trabajadores calificados y no calificados para las distintas regiones mexicanas. En el caso de México, se ha determinado la persistencia de una gran brecha y desigualdad en los salarios de los calificados y no calificados en el contexto de la apertura comercial (Castro, 2007, López-Acevedo 2005, Meza 2001 y 2003), al mismo tiempo que la apertura comercial y la privatización han tenido efectos negativos en la producción nacional y el empleo, generando subempleo no sólo en los trabajadores menos calificados, sino al parecer se ha extendido a los más calificados (Ramírez, 2000). Lo anterior resulta alarmante, pues el ritmo de crecimiento de los egresados universitarios se ha incrementado en las últimas décadas, al presentarse una sobreoferta de trabajo calificado en el país.

Para lograr el cometido, se emplea una técnica no paramétrica que permite describir y desagregar visualmente las características de la distribución de los salarios para cada tipo de mano de obra, permitiendo que la información hable por sí misma y sin imponer restricción alguna. A continuación se muestra el orden del artículo. En la primera parte se procede con un repaso de la literatura empírica y el enfoque teórico; la segunda sección describe la metodología y los datos empleados; la tercera aborda las técnicas utilizadas y analiza los principales resultados de su aplicación. Por último se muestran las conclusiones.

Vol. 39, núm. 154, julio-septiembre / 2008

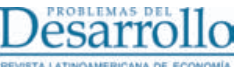




\section{Evidencia empírica y antecedentes}

A pesar de que el trabajo no calificado mantiene su presencia en segmentos económicos tradicionales tales como la agricultura o la rama de la construcción, la demanda de asalariados con pocas habilidades ha caído drásticamente en la mayor parte del mundo, y no ha sido la excepción para el caso de México (Berman, et al., 1997).

Se asume que el cambio técnico está sesgando la demanda de trabajo hacia aquellos individuos con mayor nivel de educación, de manera que el ingreso de éstos tendería a crecer en detrimento de aquéllos con menor escolaridad. Existe evidencia de que el cambio técnico sesgado afecta con mayor impacto a las ocupaciones de menor calificación laboral, lo que ha propiciado que se acentúen las diferencias salariales y la desigualdad en la mayor parte de los países y al interior de éstos, tal es el caso de Estados Unidos (EU), Alemania, España y México, entre otros (Berman, 1993; Berman, et al., 1997; Dunne, et al., 2000; Oliver, et al., 2001; y López-Acevedo, 2005).

Katz y Murphy (1991) analizan el cambio en la estructura de salarios en EU en el periodo 1963-1987, ante un rápido crecimiento de la demanda de asalariados con más educación, habilidades y también a la mayor participación de la mujer en el mercado de trabajo. En sus resultados mencionan que los cambios en la estructura de salarios se localizan en el sector industrial y favorecen a las mujeres con mayor nivel de educación. Dunne et al. (2000) analizan los cambios en la estructura de la producción, los salarios y el empleo, y sus resultados muestran que el incremento en las habilidades de los trabajadores y el cambio tecnológico producen dispersión entre los salarios y la productividad de las empresas y dentro de las mismas. De acuerdo con el autor, otro factor importante que explica dicha dispersión salarial es la inversión en equipo de cómputo por individuo.

Por su parte, Steiner et al. (1998), con los datos de seguridad social para hombres y mujeres en Alemania, observan el cambio relativo en el empleo y la estructura de ingresos de los trabajadores calificados y no calificados y sus resultados muestran una drástica caída del empleo de aquéllos con bajo nivel de calificación, debido sobre todo a la rigidez de los salarios en ese país. Para España, Oliver et al. (2001) analizan la composición del empleo por nivel educativo y por categoría profesional ante los efectos del cambio técnico sesgado y desigual. Los resultados muestran que entre 1995 y 2000 las variaciones intrasectoriales que se refieren a la productividad del trabajo y la fijación de los precios y salarios explican 70\% del avance del empleo calificado —el cual se refiere a los trabajadores con estudios de bachillerato y superior-.

\section{DeSTarrollo}

Vol. 39, núm. 154, julio-septiembre / 2008 
El $28.3 \%$ por su parte se debe a cambios en la estructura productiva -intersectorial - señalando como causa relevante la creciente apertura exterior de la economía española en los últimos años.

Meza (2003) muestra con las Encuestas Nacionales de Empleo Urbano (ENEU) y la Encuesta Industrial Anual (EIA) que durante los años noventa la apertura comercial indujo poco o nulo impacto sobre los cambios laborales en el sector manufacturero para el trabajo calificado, y concluye que son esencialmente el cambio tecnológico sesgado y factores estructurales internos los que condicionan este mercado. Ramírez (2000), con los datos de la Encuesta Nacional de Educación, Capacitación y Empleo (ENECE) de 1972 a 1997, analiza el empleo y la calificación de la mano de obra en México y sus resultados destacan que hay un desplazamiento gradual de la oferta de población trabajadora hacia la mano de obra semicalificada, sustituyendo a los asalariados menos calificados en los mismos puestos de trabajo, debido a que los empleadores suelen preferir a los candidatos con mayor escolaridad. Ramírez (2004), con los datos de la Encuesta Nacional de Empleo (ENE), así como las ENECE de 1993, 1995, 1997 y 1999, estudia los cambios en la demanda calificada asociados a la liberalización económica en México, y sus resultados muestran que existe una diferencia significativa en el mercado laboral en los años noventa en favor del trabajo calificado y de calificación intermedia.

La evidencia más reciente para México es aportada por López-Acevedo (2005) y Castro (2007) — a partir de datos de la Encuesta Nacional de Ingreso y Gasto (ENIGH) y de la ENEU respectivamente hasta el año 2002, con técnicas de descomposición-, quienes muestran que la desigualdad educativa explica la mayor parte de la variación en la desigualdad de ingresos en el mercado laboral mexicano y al interior de sus áreas metropolitanas.

Una de las hipótesis más aceptadas y probadas en estudios previos para México es la del cambio técnico sesgado (Meza, 1999, Tan y Batra, 1997, Hanson y Harrison, 1999). El estudio de Tan y Batra mide el efecto de la inversión en investigación, desarrollo y entrenamiento laboral en el entorno de las empresas con orientación exportadora, y encuentran un impacto asimétrico del cambio técnico sobre los salarios de los trabajadores calificados y no calificados, pues el efecto ha sido mayor entre los primeros en detrimento de los segundos. Hanson y Harrison (1999) examinan el impacto de la apertura comercial y sus reformas al interior de México sobre los salarios y prueban que las políticas comerciales han modificado el patrón de empleo hacia industrias que utilizan más intensivamente mano de obra calificada —el conocido teorema Stolper-Samuelson (SST) (Stolper y Samuelson,

Vol. 39, núm. 154, julio-septiembre / 2008

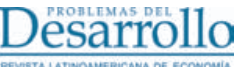


1941)—. La lógica del teorema SST para el caso mexicano parece reflejar más bien el efecto opuesto. ${ }^{1}$

En general, podemos concluir que la evidencia empírica reciente muestra que la apertura económica y las reformas institucionales sobre el mercado laboral en México sí han producido incrementos sostenidos de la desigualdad salarial con mayor precariedad del trabajo (Tan y Batra, 1997; Alarcón y McKinley, 1997; Hanson y Harrison, 1999; Maloney, 1999; Martin, 2000; Aguilar, 2000; Blunch et al., 2001; Esquivel y Rodríguez-López, 2003; y Hanson, 2003). También se han presentado rendimientos educativos crecientes que se explican por una demanda de fuerza de trabajo cada vez más calificada, debido esencialmente a dos factores: el cambio técnico sesgado y la apertura comercial (Davis, 1996; Kanbur y Lustig, 1999; Meza, 2001; Meza, 2003; Acemoglu, 2002; y Hanson, 2003).

\section{Evidencia empírica e hipótesis del trabajo}

Esta investigación plantea la hipótesis de que en México la distribución salarial se encuentra más concentrada dentro del trabajo calificado que su contraparte y con mayores diferencias en la frontera norte del país entre 2000 y 2004. La hipótesis se constituye no sólo por la tendencia de que en la frontera norte los salarios sean mayores que en el resto del país, sino porque existe una homogenización entre los salarios de los no calificados en las regiones mexicanas, en un contexto donde se presenta una disminución de la desigualdad salarial en el ámbito nacional. Se pretende probar que la reducción de la desigualdad salarial en México no es inducida por la frontera norte.

Al respecto, el estudio de Heckman y Sedlacek (1985) permite apoyar la hipótesis, al plantear la existencia de un mercado de trabajo competitivo donde los empleados interactúan simultáneamente y compiten por desarrollar sus actividades en aquel sector que más les reditúe en términos salariales. Este análisis prueba para EU la segmentación del mercado de trabajo entre el sector manufacturero y no manufacturero entre 1976 y 1980. El modelo predice una mayor heterogeneidad entre el grupo de industrias clasificadas dentro del sector no manufacturero, debido sobre todo a dos

1 El teorema Stolper-Samuelson predice que en países (en desarrollo) abundantes en trabajo, la transferencia de recursos del sector productor de bienes no comerciables al sector de bienes comerciables, en conjunto con el crecimiento del empleo y los salarios resultantes de tal efecto, deben en principio beneficiar en mayor medida (si bien de manera desproporcionada) al trabajo menos cualificado.

\section{DeSTarrollo}


causas: 1) la terciarización en aquel entonces de la economía estadounidense, y 2) la mayor proporción de asalariados ubicados en este sector (63\%). La mano de obra de la industria manufacturera representó $21 \%$ de la muestra y $16 \%$ de la fuerza laboral para el resto de la economía.

Un hallazgo importante en el estudio previo es que las estimaciones revelaron que la educación y la mayor experiencia, si bien aumentan la probabilidad de participación en el mercado laboral, tuvieron un efecto algo mayor para el sector no manufacturero. La mayor competencia en este ámbito permitió una mejor asignación del trabajo, y una mano de obra más calificada era requerida en el sector de los servicios de EU a pesar de que la evidencia empírica mostrara un mayor promedio en las remuneraciones de la industria manufacturera (Heckman y Sedlaceck, 1985). Esta evidencia demuestra que los salarios del trabajo menos calificado tienden a homogeneizarse con el tiempo, en tanto que el premio a la labor calificada es superior, y también su dispersión.

En el caso de México y si se considera la posición del trabajo calificado, hay evidencia que apoya la hipótesis de mayor precariedad del empleo formal generado en la década de los noventa y — como respuesta — una mayor participación del trabajo calificado en el sector informal (Maloney, 1999; Gong y Van Soest, 2001; Maloney, 2002; y Huesca, 2008a).

\section{Metodología y datos empleados}

Las bases de datos de las ENEU 2000 y $2004^{2}$ son la materia prima esencial en esta investigación. Las ENEU son encuestas que desagregan la información tanto de empleo como de remuneraciones en el nivel de microdatos en un panel rotativo (con duración de cinco trimestres); sin embargo, para el análisis empírico sólo se empleará la información al tercer trimestre con el objetivo de crear un corte transversal representativo entre los años estudiados. Se procedió a homologar las ciudades al utilizar como referencia las contenidas en la encuesta de 2004, ello fue necesario para hacer una comparación más objetiva en el periodo analizado, al cubrir a $61 \%$ de la población en áreas urbanas hasta con al menos 2,500 habitantes, y a 92\% de la población que vive en áreas metropolitanas con 100 mil o más habitantes.

2 A partir de 2005 las ENEU cambian a una mayor cobertura que incluye las zonas rurales, consolidando el proyecto en las Encuestas Nacionales de Ocupación y Empleo (ENOE).

Vol. 39, núm. 154, julio-septiembre / 2008

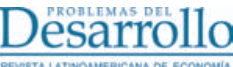


Se consideran las 34 ciudades que se mantienen incluidas en ambas encuestas y a partir del estudio de Hanson (2003) se han conformando las regiones: frontera, norte, centro, capital, sur y península. ${ }^{3}$

Se utilizaron los criterios de Meza (2001) y Sandoval (2004) para seleccionar a los asalariados calificados con al menos 12 años de escolaridad terminada, y los no calificados con un nivel de estudios inferior a $12 .{ }^{4} \mathrm{Si}$ bien la definición del trabajo calificado y no calificado se aprecia limitada, al no relacionarla con otros atributos del trabajador y su tipo de ocupación, se ha decidido establecerla en esa forma, pues permitirá el contraste con la evidencia empírica de otros estudios.

Los salarios de los trabajadores son captados por la encuesta de forma mensual en pesos corrientes mexicanos. En el estudio empírico se calculan los salarios reales en dólares estadounidenses a precios del año 2000 referidos al tercer trimestre, al deflactarlos por el Índice de Precios al Consumidor por estratos de salario del Banco de México ${ }^{5}$ al dividir su valor por el tipo de cambio promedio del peso por el dólar en el mismo trimestre.

\section{Estructura de la ocupación calificada y no calificada}

De acuerdo con el análisis de las ENEU y el tratamiento en sus bases de datos, se puede apreciar en el cuadro 1 que los trabajadores asalariados no calificados tienen el mayor peso en el país, con algo más de 70\% del total, y que sus regiones presentan distinciones relevantes.

La información ha sido tabulada por poblaciones con los factores de expansión de las encuestas. Se observa que la capital presenta la mayor cantidad de trabajo por regiones por encima de $40 \%$, seguida de la del centro y la frontera, y que de manera conjunta suman algo más de $80 \%$ del empleo urbano total en el país.

3 Las regiones se integran al considerar las mismas ciudades incluidas en la muestra de la respectiva entidad en ambas encuestas con el siguiente orden: frontera: Baja California, Sonora, Chihuahua, Coahuila, Nuevo León y Tamaulipas; norte: Aguascalientes, Baja California Sur, Durango, Nayarit, San Luis Potosí, Sinaloa y Zacatecas; centro: Colima, Guanajuato, Hidalgo, Jalisco, Michoacán, Morelos, Puebla, Querétaro, Tlaxcala y Veracruz; capital: Distrito Federal y México; Sur: Chiapas, Guerrero y Oaxaca; península: Campeche, Tabasco, Quintana Roo y Yucatán.

4 Se seleccionan individuos entre 16 y 65 años de edad, según la escolaridad para trabajadores calificados y no calificados.

5 Los estratos se expresan en salarios mínimos y se ajusta su variación al cambio de base $2000=100$.

\section{DeSTarrollo}

Vol. 39, núm. 154, julio-septiembre / 2008 
Cuadro 1

Estructura de la ocupación calificada y no calificada de asalariados por regiones en México 2000 y 2004

\begin{tabular}{lrrrrr}
\hline Regiones & Calificados & $\%$ & No calificados & $\%$ & \multicolumn{1}{c}{ Total } \\
\hline Frontera & 589,666 & 16.2 & $1,527,513$ & 19.5 & $2,117,179$ \\
Norte & 286,678 & 7.9 & 522,410 & 6.7 & 809,088 \\
Centro & 838,782 & 23.0 & $1,841,403$ & 23.5 & $2,680,185$ \\
Capital & $1,589,025$ & 43.6 & $3,370,797$ & 43.1 & $4,959,822$ \\
Sur & 155,158 & 4.3 & 222,362 & 2.8 & 377,520 \\
Península & 184,741 & 5.1 & 341,286 & 4.4 & 526,027 \\
Total & $3,644,050$ & 100.0 & $7,825,771$ & 100.0 & $11,469,821$ \\
\hline \multicolumn{5}{c}{2004} \\
\hline Frontera & 627,188 & 17.2 & $1,556,565$ & 19.9 & $2,183,753$ \\
Norte & 331,874 & 9.1 & 520,539 & 6.7 & 852,413 \\
Centro & 863,849 & 23.7 & $1,749,062$ & 22.4 & $2,612,911$ \\
Capital & $1,692,473$ & 46.4 & $3,237,201$ & 41.4 & $4,929,674$ \\
Sur & 191,482 & 5.3 & 243,124 & 3.1 & 434,606 \\
Península & 231,864 & 6.4 & 367,796 & 4.7 & 599,660 \\
Total & $3,938,730$ & 100.0 & $7,674,287$ & 100.0 & $11,613,017$ \\
\hline
\end{tabular}

Fuente: Elaboración propia con la base de datos de la ENEU, años respectivos.

La distribución del trabajo calificado refleja un incremento en el periodo analizado al ubicarse en $46.4 \%$, seguida de la centro y la frontera con $23.7 \%$ y $17.2 \%$ en cada caso. La región norte indica un nivel de $9.1 \%$, dejando los restantes $6.4 \%$ y $5.3 \%$ a las regiones de la península y del sur. El trabajo no calificado muestra una distribución similar, tan sólo con una proporción relativa superior en la región frontera. Entre las posibles causas que originan esta distribución de la mano de obra, con los mismos datos y criterio, se observa un crecimiento del empleo no calificado en la industria maquiladora y manufacturera por encima del trabajo calificado en la región de la frontera (Castro, 2007). También este hallazgo podría ser explicado por el movimiento de municipios en la muestra que el propio Instituto Nacional de Estadística, Geografía e Informática (INEGI) ha realizado en el levantamiento de la encuesta, y que de acuerdo con el estudio de Castro (2007) también se presenta debido al peso que ejercen las ciudades ubicadas sobre la línea fronteriza, que son las que han perdido mayor proporción de trabajo calificado, sobre todo desde 1992 a 2002. Otro fenómeno alterno es la emigración de trabajo calificado en esta región, pues, según el estudio de 
Huesca (2008b), la probabilidad de emigrar fuera del país en esta zona es creciente con la escolaridad, con mayores impactos en los niveles educativos superiores.

El cuadro 2 muestra las remuneraciones medias por regiones y se puede observar que entre los años analizados todas las regiones han mantenido -incluso incrementado- - su poder adquisitivo. Tal es el caso de las regiones norte, sur y península con cambios superiores; sin embargo, la región de la frontera mantiene el nivel salarial mayor con 478 dólares. Otro aspecto relevante es la reducción de la dispersión en las remuneraciones para la mayoría de las regiones, donde destaca la frontera y el sur con los mayores cambios, como señal de salarios más homogéneos al interior de ellas. Al considerar esta evidencia es muy aventurado concluir aquí una hipótesis de mayor homogeneidad salarial al respecto. Por ello procedemos a describir los promedios salariales por las características del trabajo y nivel educativo, para estar en condiciones, en la sección posterior, de analizar las distribuciones en su totalidad y por subgrupos de regiones y tipo de mano de obra.

Cuadro 2

Salarios mensuales promedios en México y por regiones 2000 y 2004 (USD 2000=100)

\begin{tabular}{|c|c|c|c|c|}
\hline & \multicolumn{2}{|c|}{2000} & \multicolumn{2}{|c|}{2004} \\
\hline & Media & Desv. estándar & Media & Desv. estándar \\
\hline Distribución total & 371 & 429 & 401 & 398 \\
\hline \multicolumn{5}{|c|}{ Regiones } \\
\hline Frontera & 431 & 463 & 478 & 482 \\
\hline Norte & 334 & 319 & 390 & 379 \\
\hline Centro & 337 & 323 & 376 & 351 \\
\hline Capital & 378 & 489 & 390 & 388 \\
\hline Sur & 294 & 289 & 336 & 295 \\
\hline Península & 345 & 342 & 388 & 389 \\
\hline
\end{tabular}

Fuente: Elaboración propia con la base de datos de la ENEU, años respectivos.

El cuadro 3 presenta las remuneraciones medias por tipo de labor entre los años analizados. En el país se observa que el trabajo calificado y el no calificado en 2004 tienen una remuneración media de 595 y 302 dólares respectivamente, lo que refleja un incremento de $1.5 \%$ y $15 \%$ en el periodo. Es relevante el incremento real en la re-

\section{DeSTarrollo}

Vol. 39, núm. 154, julio-septiembre / 2008 
muneración media del trabajo no calificado, sobre todo el presentado en las regiones del norte, capital, península y centro, y en menor medida la del sur y la frontera norte. La distribución se ha convertido más homogénea dentro del trabajo no calificado como podremos comprobarlo más adelante; por su parte el trabajo calificado sólo mostró un incremento sustancial en el norte, y menor magnitud en el sur y península, con una reducción considerable para la capital por el orden de 9.8\%.

Cuadro 3

Salarios mensuales promedios por tipo de calificación en México y por regiones 2000 y 2004 (USD 2000=100)

\begin{tabular}{|c|c|c|c|c|c|c|c|c|}
\hline & \multicolumn{4}{|c|}{2000} & \multicolumn{4}{|c|}{2004} \\
\hline & \multicolumn{2}{|c|}{ Calificados } & \multicolumn{2}{|c|}{ No calificados } & \multicolumn{2}{|c|}{ Calificados } & \multicolumn{2}{|c|}{ No calificados } \\
\hline & Media & Desv. estándar & Media & Desv. estándar & Media & Desv. estándar & Media & Desv. estándar \\
\hline Distribución total & 586 & 639 & 262 & 207 & 595 & 568 & 302 & 213 \\
\hline \multicolumn{9}{|c|}{ Regiones } \\
\hline Frontera & 718 & 714 & 320 & 236 & 770 & 745 & 361 & 233 \\
\hline Norte & 490 & 438 & 249 & 179 & 547 & 510 & 289 & 209 \\
\hline Centro & 525 & 469 & 251 & 167 & 545 & 488 & 293 & 214 \\
\hline Capital & 650 & 735 & 249 & 215 & 586 & 551 & 287 & 201 \\
\hline Sur & 419 & 373 & 207 & 161 & 461 & 370 & 237 & 161 \\
\hline Península & 529 & 464 & 246 & 191 & 555 & 528 & 282 & 206 \\
\hline
\end{tabular}

Fuente: Elaboración propia con la base de datos de la ENEU, años respectivos.

Por tipo de trabajo calificado y no calificado se observa que la región de la frontera presenta un salario promedio por encima del nacional, mientras que el resto se ubica por debajo, si bien con distinta magnitud, siendo las más afectadas las zonas sur, norte y centro. La frontera presenta la media de las remuneraciones más alta en los dos años para ambos colectivos laborales; le sigue la capital, centro, península y norte, en tanto que la sur presenta los valores más reducidos. La dispersión medida por la desviación estándar de los promedios para los calificados indica mayor distancia en la región de la frontera, señal de mayor heterogeneidad al interior del tipo de trabajo calificado con respecto del resto de las regiones. Resalta la reducción drástica en la dispersión para el trabajo no calificado en la región sur en el periodo, como señal de menor dispersión en las estructuras salariales dentro del colectivo no calificado. 
En cuanto a la escolaridad no se observan cambios sustanciales debido al periodo analizado que relativamente es corto, sólo el hecho de que la región sur observa los promedios educativos más reducidos para el colectivo no calificado, con 6.7 años logrados, en tanto que la frontera presenta el caso opuesto, con ocho años de escolaridad en el mismo colectivo y una menor dispersión.

Cuadro 4

Escolaridad de los trabajadores calificados

y no calificados en México entre 16 y 65 años de edad

\begin{tabular}{|c|c|c|c|c|c|c|c|c|}
\hline \multirow{4}{*}{$\begin{array}{l}\text { Variables medias } \\
\text { México }\end{array}$} & \multicolumn{4}{|c|}{2000} & \multicolumn{4}{|c|}{2004} \\
\hline & \multicolumn{2}{|c|}{ Calificados } & \multicolumn{2}{|c|}{ No calificados } & \multicolumn{2}{|c|}{ Calificados } & \multicolumn{2}{|c|}{ No calificados } \\
\hline & \multicolumn{2}{|c|}{ Escolaridad desv. estándar } & \multicolumn{2}{|c|}{$\overline{\text { Escolaridad desv. estándar }}$} & \multicolumn{2}{|c|}{$\overline{\text { Escolaridad desv. estándar }}$} & \multicolumn{2}{|c|}{ Escolaridad desv. estándar } \\
\hline & 15.2 & 2.3 & 7.4 & 2.9 & 15.1 & 2.4 & 7.5 & 2.8 \\
\hline \multicolumn{9}{|c|}{ Regiones } \\
\hline Frontera & 15.5 & 2.1 & 7.8 & 2.7 & 15.4 & 2.3 & 7.9 & 2.6 \\
\hline Norte & 15.2 & 2.2 & 7.5 & 2.9 & 15.1 & 2.3 & 7.7 & 2.8 \\
\hline Centro & 15.1 & 2.3 & 7.2 & 2.9 & 15.0 & 2.5 & 7.3 & 2.9 \\
\hline Capital & 15.1 & 2.4 & 7.7 & 2.8 & 15.0 & 2.4 & 7.6 & 2.8 \\
\hline Sur & 15.2 & 2.2 & 6.7 & 3.3 & 15.0 & 2.4 & 6.7 & 3.1 \\
\hline Península & 15.0 & 2.3 & 7.2 & 3.0 & 14.8 & 2.4 & 7.3 & 3.0 \\
\hline
\end{tabular}

Fuente: Elaboración propia con base en los datos de la ENEU 2000 y 2004.

\section{Aplicación empírica}

El objetivo central de esta sección es profundizar en el análisis de los salarios entre 2000 y 2004 para el trabajo calificado y no calificado en México y sus regiones, con énfasis en la frontera, y evaluar si los cambios en las remuneraciones han seguido un patrón similar o distinto al nacional.

\section{La distribución salarial en México: 2000 y 2004}

Durante 2000 y 2004 se presenta un periodo relevante de análisis para evaluar los salarios en México y sus regiones: el cambio presidencial en México y el año 2001 con la recesión económica en EU, aunado a incrementos salariales por el orden acumulado de 23.2\% (Comisión Nacional de Salarios Mínimos) en un contexto donde los indicadores macroeconómicos de la economía mexicana han tendido a estabilizarse.

Con el objetivo de analizar la distribución de las remuneraciones, en una primera etapa acudimos a una técnica tradicional que permite realizar la comparación de dis- 
tribuciones mediante la estimación de curvas de Lorenz (Kakwani, 1984), la cual en su forma continua se obtiene con la siguiente expresión: ${ }^{6}$

$$
L_{F}(p)=\int_{0}^{1} \frac{x f(x) d x}{\mu}, 0<p<1 ; L_{F}(p) \in[0,1]
$$

Donde $p$ es una proporción de los individuos en observación con ingresos $x$ normalizados por la media, menores o iguales a 1 y que tienen como función de distribución $F$. En otras palabras, es la suma acumulada de todos los ingresos relativos a la media para cada proporción de población $p$. Este análisis proporciona una idea de la distancia de salarios entre los grupos considerados, y que en el caso de igualdad se obtendría el máximo valor de igualdad salarial $L_{F}(p)$ entre los individuos y que define la recta de equidad en $45^{\circ}$.

Para determinar consistentemente y sin ambigüedad si una distribución $F$ muestra más distancia (y mayor dispersión) que otra $G$ con respecto de la equidad, esto es, $L_{F}$ $(p)>L_{G}(p)$, se procede a obtener las siguientes diferencias para cada valor de $L(p)$ :

$$
L_{F}(p)-L_{G}(p)=L(F)-L(G) \quad, \quad \forall L_{F}(p)>0,(2)
$$

Para todo $p$ perteneciente al rango [0,1], el criterio nos permite ordenar las distribuciones de acuerdo con su grado de concentración relativa, y a pesar de que el ordenamiento queda indefinido cuando las curvas se cruzan (Kakwani, 1984, Lambert, 2001), estamos en condiciones de identificar el problema anterior en las diferencias al emplear microdatos de las encuestas y analizar a cada individuo en forma gráfica. Para ello, se observa en donde se producen los cruces y la relevancia de éstos sobre la distribución siguiendo el estudio de Lambert y Ramos (2002) que cuantifica la superioridad de bienestar de $G$ sobre $F$. Al reescribir la expresión anterior (2) a partir de una función de bienestar social $W(x)$ aditivamente separable con distintas funciones de utilidad $U_{i}(x)$, para todo un rango secuencial en términos de distribuciones específicas de la forma $F_{i}(x)$ y en $G_{i}(x)$ respectivamente, donde $1 \leq i \leq n$ para el caso de ser un suceso exitoso, el proceso asegura que la diferencia $L_{W}(F)-L_{W}(G)>0$ es positiva, y la curva de Lorenz de $F$ se localizará más lejos que la de $G$ y lo podremos expresar de la siguiente forma:

$$
W_{F}-W_{G}=\sum_{1 \leq i \leq n} p_{i} \int_{0}^{1} U_{i}(x)\left[f_{i}(x)-g_{i}(x)\right] d x
$$

6 La curva de Lorenz es sólo una función $p \rightarrow \mathrm{L}(p)$ convexa y creciente, es decir L' $(p)>0$ y L" $(p)>0$, lo que implica necesariamente que $p>L(p) \forall p \in(0,1)$. 
Entonces será posible cuantificar la superioridad en bienestar de $G$ sobre $F$ que deriva de la expresión (2).

\section{La concentración salarial en México y la frontera norte}

Se parte de la comparación entre las distribuciones de los salarios en el país y de la región de la frontera, al ser esta última la zona con mayor nivel de remuneración media al trabajo calificado; en una segunda etapa se procede con el análisis de los cambios producidos y el comparativo con el resto de las regiones.

La gráfica 1 exhibe la concentración de la distribución salarial de los trabajadores urbanos para México y la frontera entre 2000 y 2004. Se observa en ambos casos que los niveles de concentración se han reducido, y con cambios de mayor magnitud para la zona fronteriza.

Sin embargo, en términos del criterio de Lorenz y de dominancia (Lambert, 2001), no podemos concluir nada sobre una disminución proporcional de la concentración de

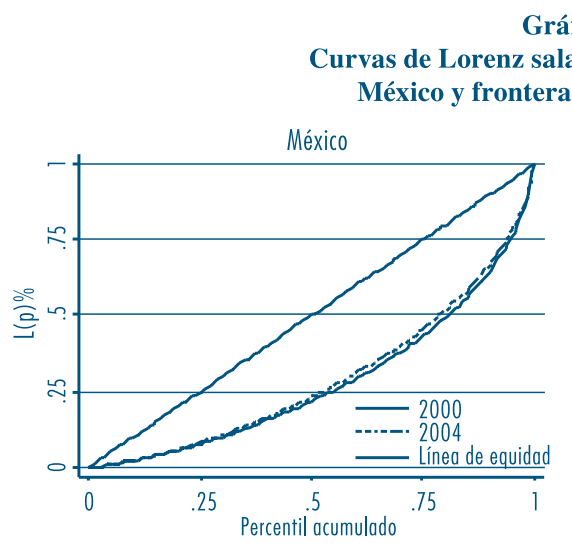

Gráfica 1

urvas de Lorenz salariales y sus diferencias

y frontera norte, 2000 y 2004
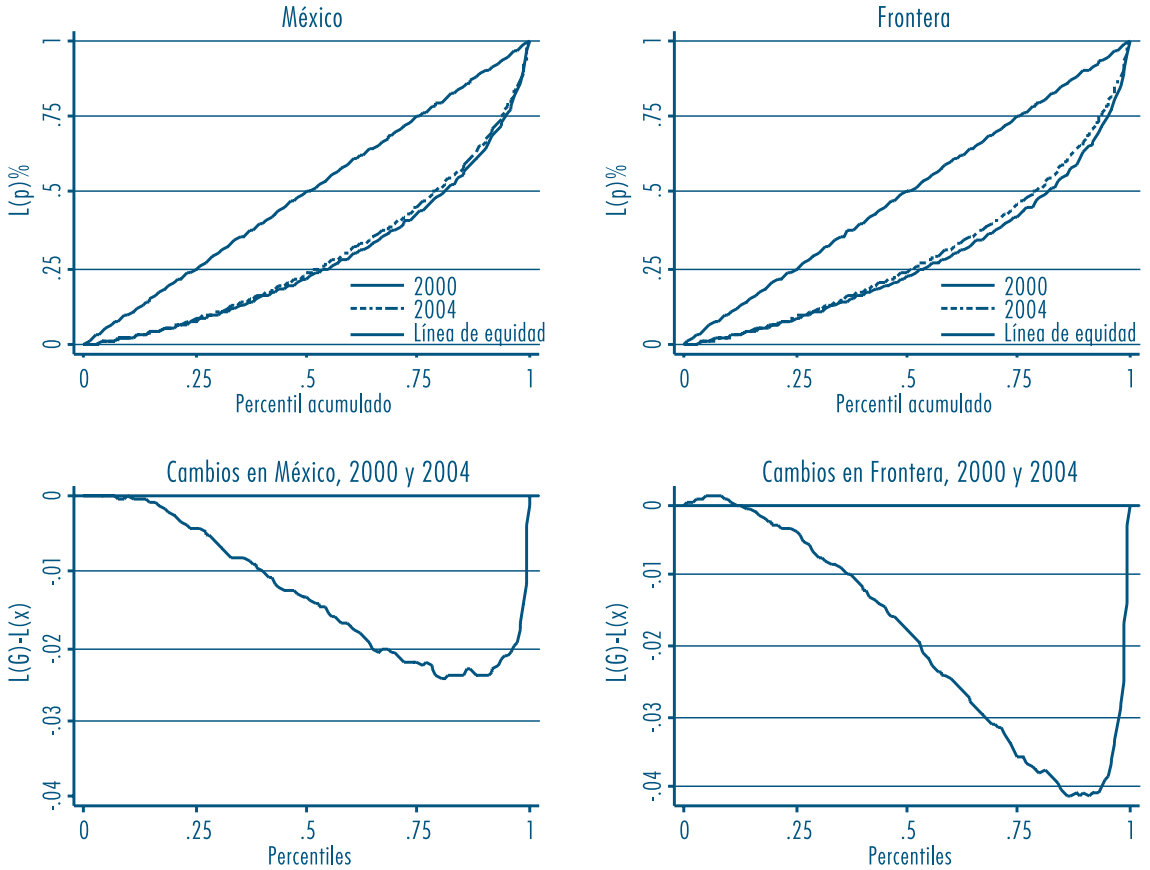

Fuente: Elaboración propia con la base de datos de la ENEU, para los años respectivos.

\section{Desaarrollo}

Vol. 39, núm. 154, julio-septiembre / 2008 
las remuneraciones entre ambos años, al cruzarse las curvas en la parte baja de la distribución, como se puede apreciar en la gráfica 1. Los cambios son más pronunciados para la frontera norte, señal de una mayor reducción de la desigualdad de los salarios en esta región; en este punto de análisis no es posible concluir cuáles han sido los impactos provocados por tipo de trabajo en estos movimientos; por ello procedemos a desagregar el análisis por las características de mano de obra calificada y no calificada.

La evidencia permite anticipar que en la categoría laboral calificada en México se presentan factores de eficiencia en el trabajo, que si bien premian en mayor medida a los individuos, inducen de manera simultánea mayor dispersión en su distribución, lo que genera mayor nivel de desigualdad que su contraparte no calificada. Entre las regiones frontera y México las distancias se han ampliado hasta llegar a un nivel extremadamente similar, lo que permite inferir, con las gráficas 2 y 3 , que las distancias fueron mayores para la frontera que el resto del país en el año 2000, mientras que en 2004 se han alineado con mayor nivel de desigualdad.

Grafica 2

Curvas de Lorenz salariales y sus diferencias por tipo de trabajo calificado y no calificado en México y frontera norte, 2000
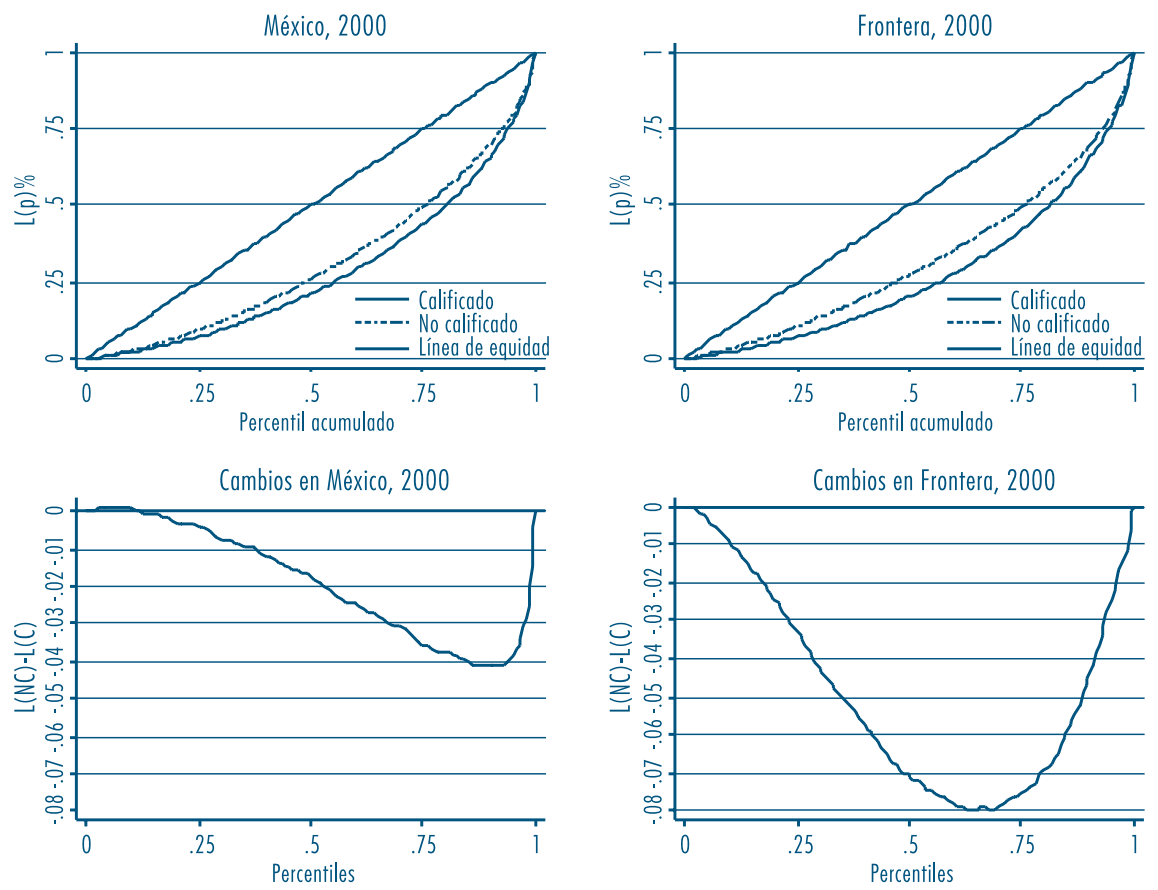

Fuente: Elaboración propia con la base de datos de la ENEU, para los años respectivos. 
El hallazgo relevante es que en años recientes se han alineado las distancias entre el país y la frontera norte para la mano de obra calificada y no calificada. Éstas presentan diferencias notables al inicio y se igualan en 2004 sin cruce alguno. De acuerdo con Castro (2007), se ha presentado una reducción de las diferencias entre los trabajadores calificados y no calificados, y señala como causas: 1) la mayor oferta relativa de asalariados calificados que afectó su salario a la baja, y 2) una contracción en la demanda de este tipo de mano de obra.

Nuestros resultados presentan un incremento de la inequidad al interior del grupo calificado, y entre sus motivos se puede considerar un aumento en la heterogeneidad de la mano de obra calificada, así como también un aumento relativo en los salarios por un efecto regional; donde los trabajadores de la frontera reciben mayores salarios que los de otras regiones en el país. Para ello procedemos en la siguiente sección a realizar un análisis de las funciones de densidad de los salarios, estimando de forma no paramétrica los cambios ocurridos para toda la distribución y su respectiva descomposición regional en el periodo.

\section{Gráfica 3}

Curvas de Lorenz salariales y sus diferencias por tipo de trabajo calificado y no calificado en México y frontera norte, 2004.
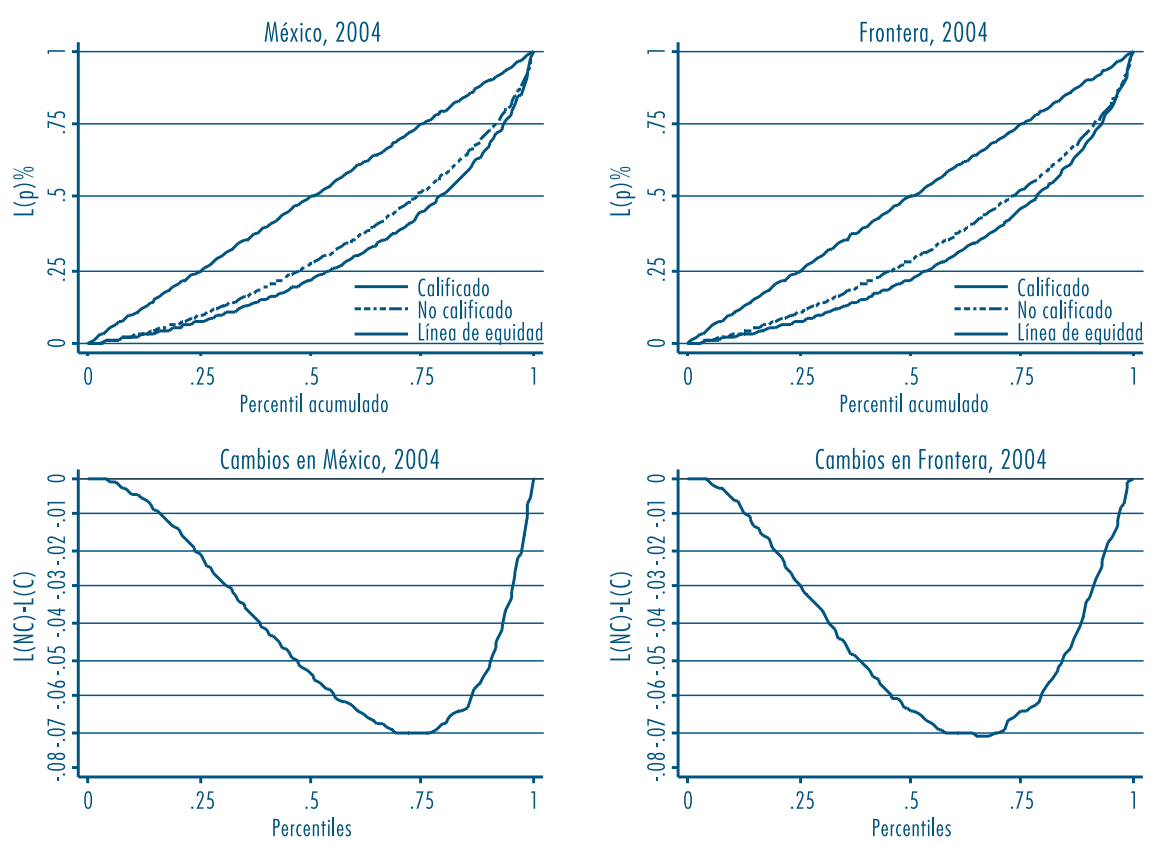

Fuente: Elaboración propia con la base de datos de la ENEU, para los años respectivos.

\section{Desaarrollo}


Estimación de las densidades y descomposición por subgrupos

La estimación de las densidades de las remuneraciones permite observar el patrón de comportamiento en las distintas funciones de densidad de probabilidad (FDP) en cualquier distribución (Silverman, 1986). Las densidades son estimadas en este estudio con la técnica no paramétrica propuesta por Jenkins y Van Kerm (2004) de tipo Kernel en su esquema adaptativo (Van Kerm, 2003), que permite suavizar — sin exceso- la densidad al evitar al máximo el "ruido" que induce la utilización de una muestra en lugar de la población total.

La utilización de este método en lugar de otras técnicas tiene varias ventajas. Si bien emplear técnicas de corte paramétrico —econométrico- puede ser útil, nos podemos enfrentar a problemas de especificación de modelos o de truncamiento de datos, sin mencionar los de tipo de sesgo de selección (Heckman, 1979). Otra ventaja relevante es la posibilidad de visualizar la descomposición de subgrupos, la cual también puede ser realizada por modelos paramétricos; empero, estos últimos sólo proveen coeficientes de impacto y, en cambio, la técnica no paramétrica de Jenkins y Van Kerm permite visualizar en su totalidad a cada subgrupo y su forma de participación en toda la densidad de ingresos, sin la necesidad de imponer tantas restricciones.

Una ventaja adicional es que este método permite desagregar - y visualizar- no sólo los subgrupos que subyacen y componen la FDP total, sino también identificar los cambios operados al interior de la misma dentro de cada subgrupo poblacional. ${ }^{7}$

Finalmente, utilizar dicha técnica en lugar de otras de tipo gráfico y no paramétrico, como pueden ser los diagramas de frecuencias relativas o la propia función de densidad, tiene la preponderancia de advertir las distintas modas de los subgrupos, y observar su impacto conjunto sobre la función de distribución poblacional, pues es común que en el trabajo empírico las distribuciones de los subgrupos sean siempre unimodales.

\section{Cambios en la distribución total y por subgrupos en las regiones mexicanas}

En primera instancia, se estiman las densidades de las distribuciones para los años analizados — 2000 y 2004—. El primer paso consiste en estimar empíricamente las funciones de densidad para la población en su conjunto y para cada subgrupo, empleando

7 En este caso, primero se obtiene la estimación de las densidades por subgrupos en función de su participación ponderada por sus pesos, de tal forma que la función de densidad para cada remuneración individual $x$ es una suma ponderada de cada FDP en todos los subgrupos $k$. 
un estimador Kernel del tipo adaptativo. ${ }^{8}$ En la gráfica 4 se muestran las estimaciones de las densidades empíricas de las remuneraciones de los trabajadores en México. Los cambios de las distribuciones son relevantes, pues sufrieron un desplazamiento hacia la derecha como señal de un incremento de las remuneraciones, al parecer para toda la población; sin embargo, en este punto de análisis es difícil identificar qué subgrupos (regiones o tipo de trabajo en nuestro caso) han sido los causantes del movimiento tanto en la parte inferior como por encima de la media de las remuneraciones (línea vertical en 406 dólares de 2004). El desplazamiento se verifica al observar el panel B donde se descubren cambios negativos en la densidad en la parte baja y cambios positivos antes de la media de la distribución.

Gráfica 4

Función de densidad salarial y sus diferencias en México, 2000 y 2004.
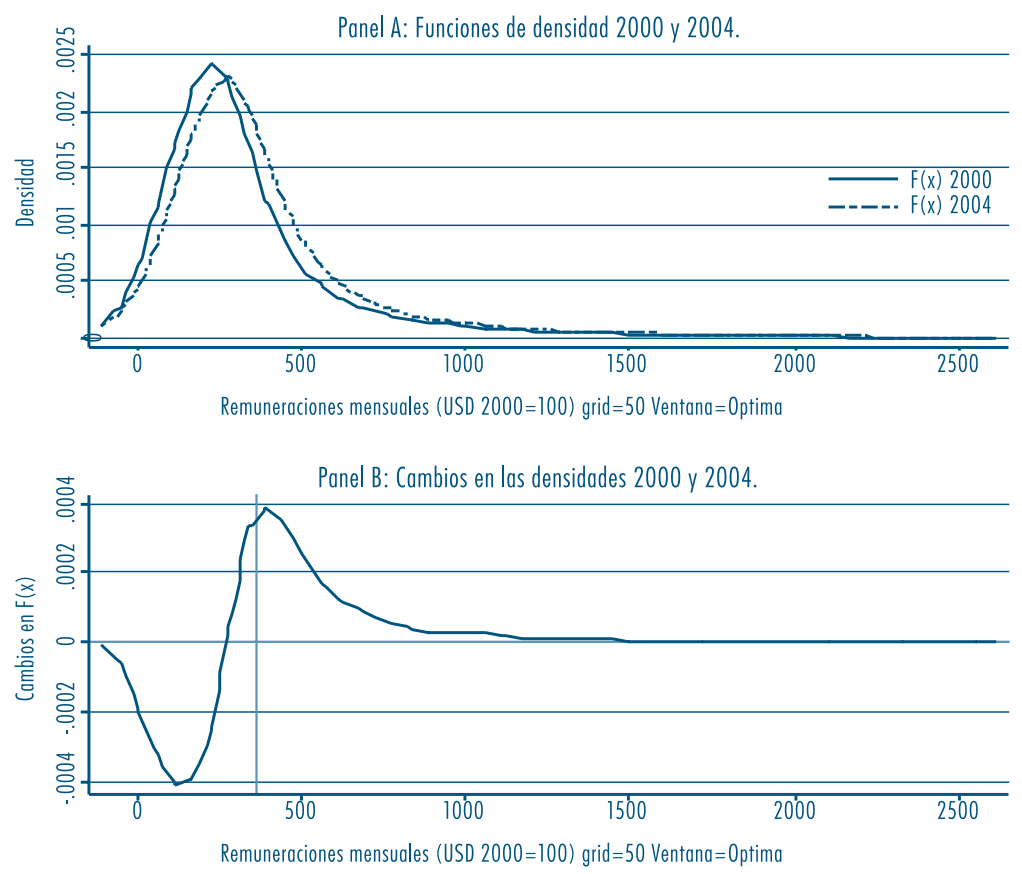

Fuente: Elaboración propia con la base de datos de la ENEU, para los años respectivos.

8 La ventaja de este tipo de estimador es que permite no suavizar en exceso la distribución en aquellas zonas de alta concentración de ingresos, al mismo tiempo que deja mantener una reducida variabilidad de los puntos estimados en donde la información de los datos es escasa, como, por ejemplo, en los rangos más elevados de salarios (Van Kerm, 2003, Jenkins y Van-Kerm, 2004).

\section{Desaarrollo}

Vol. 39, núm. 154, julio-septiembre / 2008 
Gráfica 5

Descomposición de la densidad salarial por regiones*

en México, 2000 y 2004
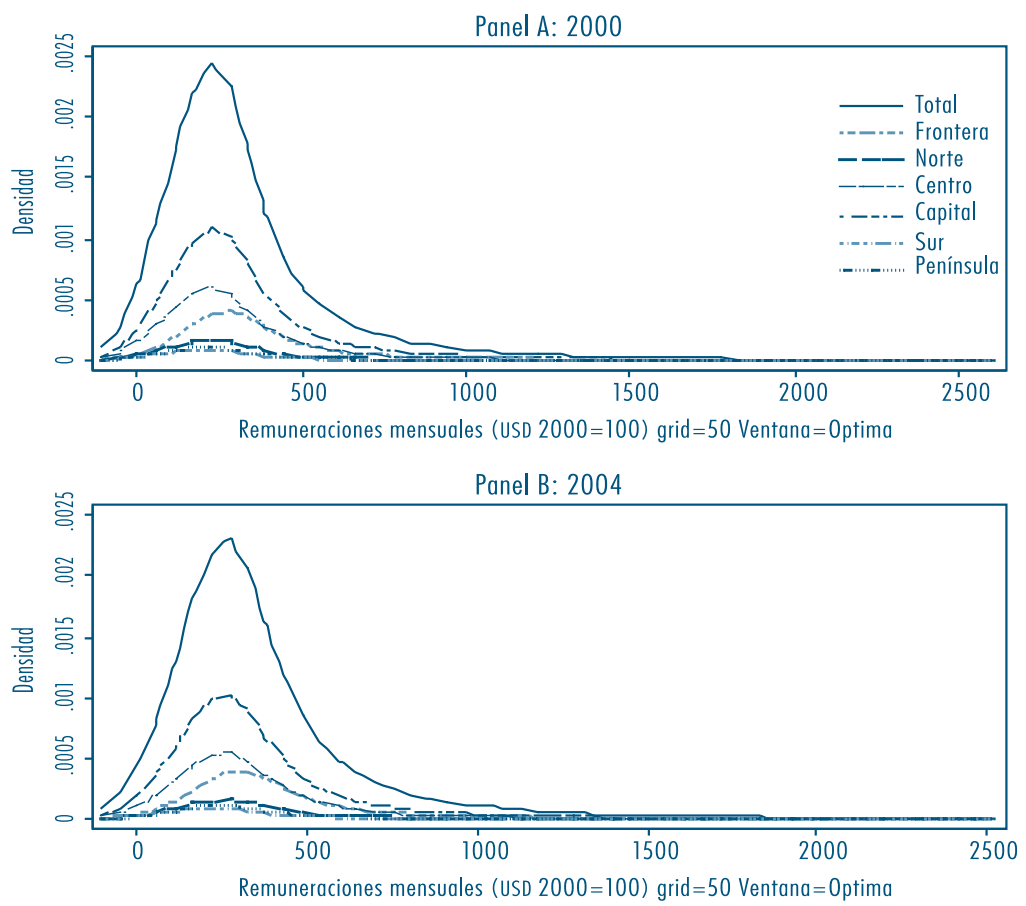

* Regionalización de acuerdo con Hanson, 2003.

Fuente: Elaboración propia con la base de datos de la ENEU, para los años respectivos.

Para analizar por subgrupos de interés que modificaron la distribución en 2004 y su sentido de movimiento, a continuación se estima la descomposición de las densidades y sus remuneraciones, cuyos resultados se observan en las gráficas 5-7. En la 5 se observa que la capital presenta influencia relevante sobre la distribución, donde la reducción de la moda en su forma se presenta por una gradual reducción de peso de la capital, y sumado al efecto de la región frontera norte y la norte en las remuneraciones, la distribución se ha desplazado hacia la derecha. Para confirmar lo anterior, se obtienen las diferencias de las densidades, de tal suerte que estamos en condiciones de hacer comparables los cambios con el resto de las regiones y con el país. En la gráfica 6 se puede observar que los cambios más relevantes se presentan para la región capital con una reducción en su moda en el periodo, y seguidamente en la frontera norte, que modificó la densidad hacia la derecha y por encima de la media de la distribución seguida de la región norte. 
Los cambios en la densidad para las regiones van en el mismo sentido pero con distinta intensidad, ya que la región centro y capital presentan cambios más densos en la parte baja como señal de mayor proporción de trabajadores que ahora han mejorado sus salarios. Por su parte, la frontera presenta mano de obra con cambios que reflejan mayor nivel de remuneraciones, al observar que la moda del cambio se

\section{Gráfica 6}

Cambios en la densidad de las remuneraciones en México y sus regiones 2000 y 2004
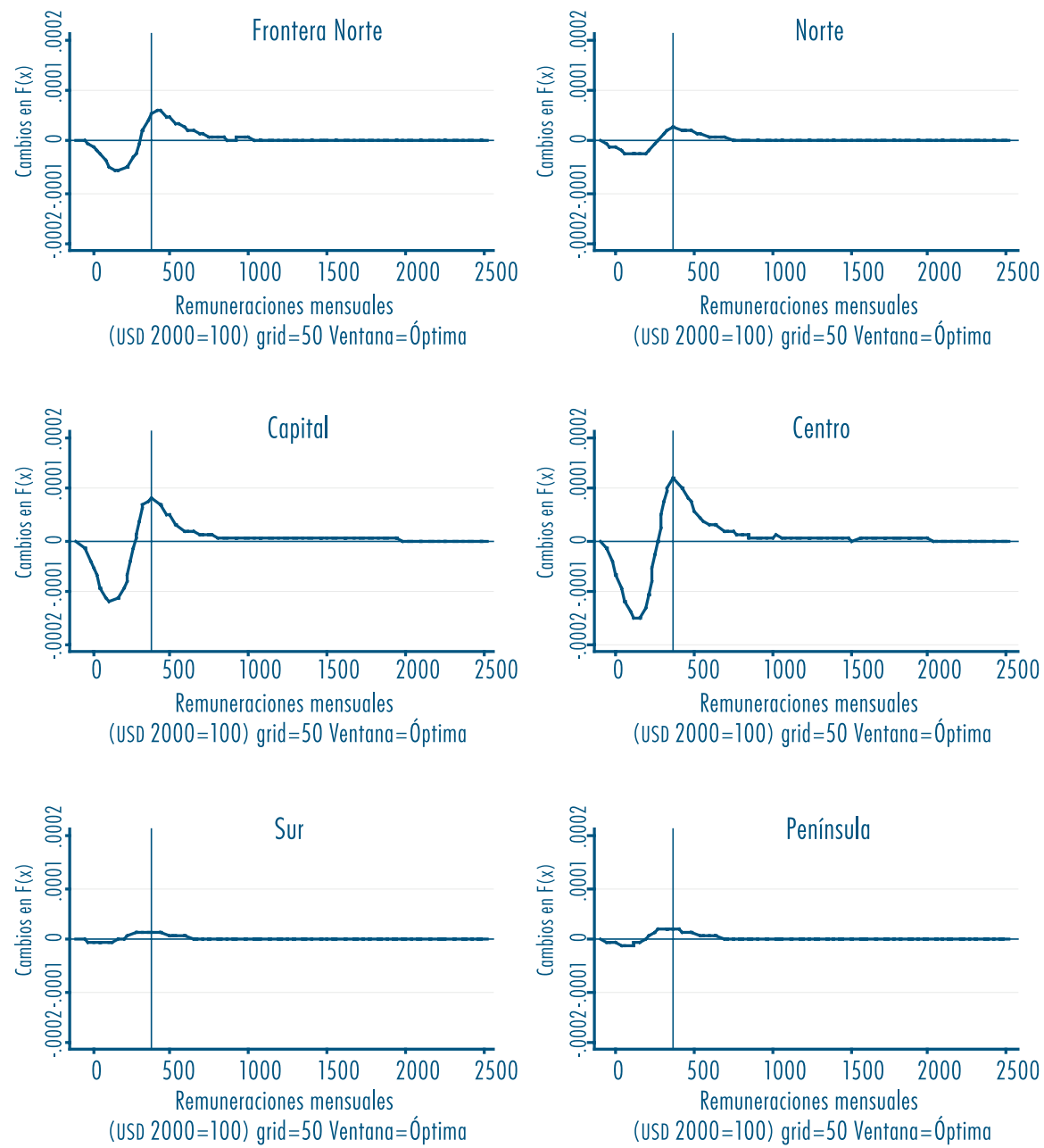

Fuente: Elaboración propia con la base de datos de la ENEU, para los años respectivos.

\section{Desarrollo}

Vol. 39, núm. 154, julio-septiembre / 2008 
produce después de la línea vertical que refleja el punto del salario promedio de 2004. Las regiones norte, sur y península reflejan cambios de menor peso sobre la densidad, y por debajo de la media salarial del año referido.

Al vincular la evidencia del Panel B en las gráficas 4 y 6 , podemos inferir con certeza que la influencia de los movimientos en los salarios entre los años 2000 y 2004 ha sido generada en gran medida por la frontera, el norte y la capital, regiones que registraron promedios en sus remuneraciones por el orden de 467, 401 y 394 dólares respectivamente y el mayor peso poblacional. Las formas de las variaciones presentan una estrecha similitud, cambios negativos en la parte baja (hasta 250 dólares) con mayor peso para la capital y de cambios positivos en las tres regiones.

\section{Análisis de los cambios por tipo de trabajo}

Como se planteó al inicio del artículo, queda fuera del alcance en esta investigación inferir sobre otras causas que seguramente han repercutido en la inequidad y el comportamiento de las brechas de salarios entre y al interior de los grupos de trabajadores; sin embargo, en este nivel de análisis es posible desagregar aún más el conocimiento de los impactos que motivaron dicho movimiento en las densidades regionales de los colectivos de asalariados considerados. Con lo anterior, sólo se busca probar la hipótesis del efecto del trabajo calificado sobre el no calificado. Para ello, acudimos en esta parte a descomponer las densidades y nos enfocamos en la frontera y su impacto en relación con el total nacional.

La gráfica 7 muestra los cambios y la descomposición de las densidades por tipo de ocupación entre mano de obra calificada y no calificada, tanto para México como para la frontera. En el ámbito nacional, a partir de salarios por encima de 500 dólares, los trabajadores calificados presentan mayor impacto en los cambios, y en la frontera ocurre en salarios por arriba de 800 dólares, señal que soporta la mayor dispersión salarial dentro de este colectivo; en cambio, los no calificados muestran una disminución significativa de la densidad y el mayor incremento en niveles inferiores a la media de la distribución y por debajo de los 500 dólares. La frontera refleja que los no calificados presentan cambios positivos en su densidad por arriba de los 250 dólares, al lograr su nivel máximo en alrededor de los 400.

Esta evidencia pone de manifiesto que los trabajadores calificados en la frontera norte se encuentran en mejores condiciones que su contraparte, considerando que a partir de 400 dólares la densidad disminuye su participación a medida que los salarios son mayores. A partir de la media nacional (línea vertical en 406 dólares), la densidad de los calificados presenta un cambio de mayor impacto para la frontera

Vol. 39, núm. 154, julio-septiembre / 2008

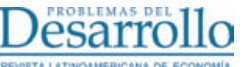


Gráfica 7

Cambios en la densidad de las remuneraciones por tipo de trabajo en México y frontera norte 2000 y 2004
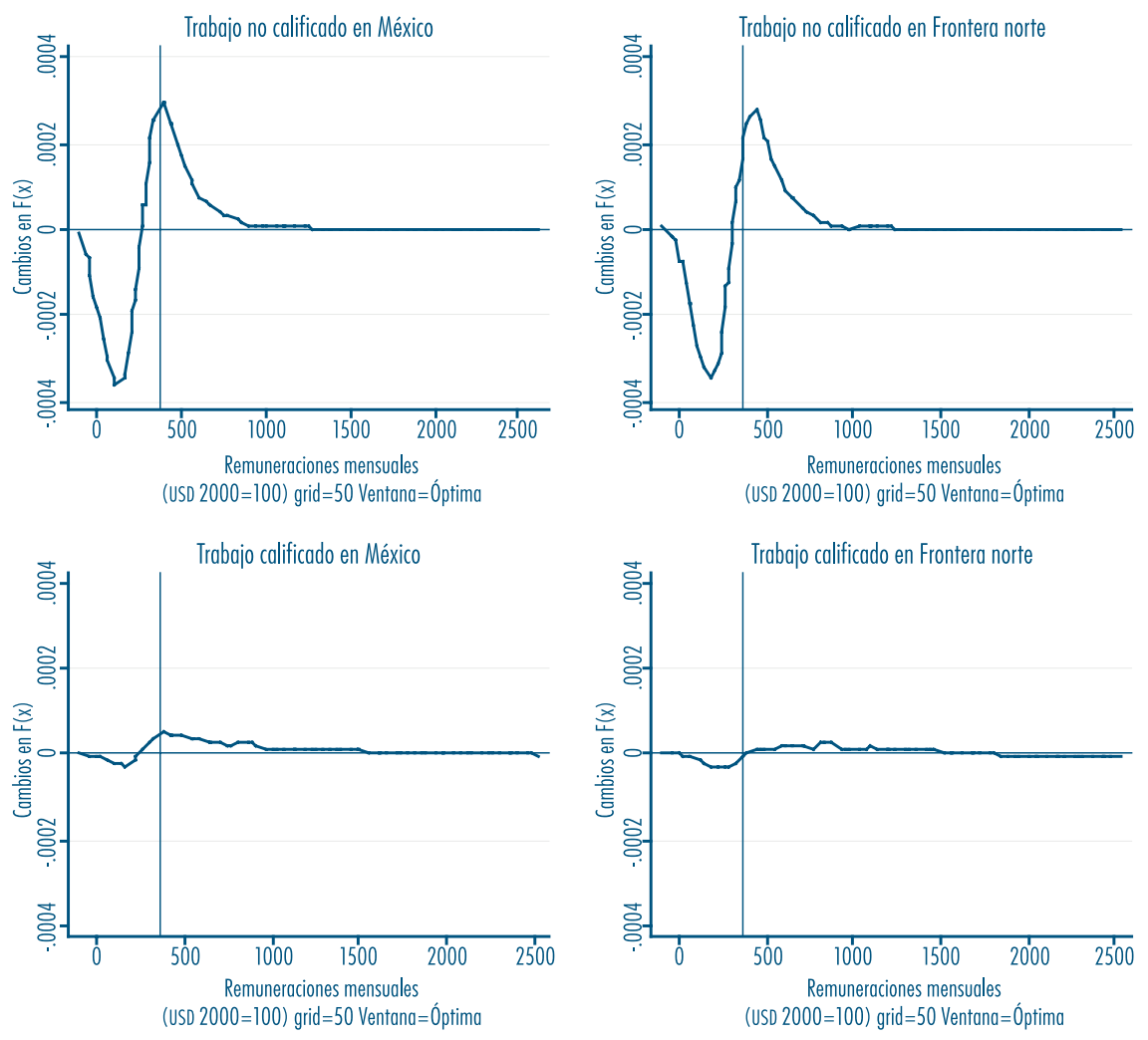

Fuente: Elaboración propia con la base de datos de la ENEU, para los años respectivos.

a diferencia de la densidad y sus cambios para México, donde éstos se producen en un nivel inferior y por debajo de la media.

La evidencia apoya la existencia del cambio técnico sesgado en favor de la mano de obra calificada y en línea con estudios previos para otros países y México (Acemoglu, 2002, Meza, 2003, y Berman et al., 1997); el hallazgo relevante de esta investigación es que no obstante la reducción en los salarios medios para el trabajo calificado en la zona norte del país, ésta se mantienen en un nivel promedio de hasta 2.35 veces superior a las registradas para el no calificado. Es un hecho, pues, que la frontera norte no ha inducido de alguna forma la reducción de la desigualdad nacional durante

\section{Desaarrollo}

Vol. 39, núm. 154, julio-septiembre / 2008 
los últimos años, sino más bien la concentración ha disminuido por parte del trabajo no calificado en otras regiones del país y este proceso está generando que se cierren las distancias salariales entre el país y la frontera.

\section{Conclusiones}

El cambio tecnológico conlleva a la transformación de productos, procesos, diseños y técnicas donde se genera innovación, la cual promueve el crecimiento económico de forma endógena en las economías. Por ello, el objetivo de la mayoría de los países y regiones en el mundo se ha centrado en la inversión en I+D y en capital humano, que infiere un mayor uso del trabajo calificado en detrimento del no calificado.

México presenta una abundante oferta de trabajo con bajo nivel de calificación, en comparación con sus vecinos Canadá y EU, y se esperaba que la liberalización comercial podría haber inducido un patrón de especialización que habría incrementado la demanda relativa de éstos y, por tanto, también de sus salarios; sin embargo, la evidencia empírica muestra que no ha sucedido de tal manera. En su lugar se ha observado un aumento de las diferencias salariales entre ambos tipos de trabajadores calificados y no calificados en favor de los primeros, y la distribución salarial se ha vuelto más desigual.

El trabajo prueba que al inicio del milenio se presenta una estabilización de la desigualdad, aunque si bien se mantiene con niveles altos para el trabajo calificado, ésta se ha reducido en mayor proporción para el no calificado, lo que ha influido en la reducción de la desigualdad nacional como señal de menor dispersión en la distribución dentro de este colectivo de asalariados.

La frontera norte mexicana muestra un proceso de homogeneización en sus salarios con mayor peso para el trabajo no calificado, evidencia que contrasta con la tendencia de nuevas técnicas de producción que pudieran llevar a cabo de manera más intensiva trabajo calificado y que al parecer no ha ocurrido en años recientes; en todo caso, es la emigración —internacional — la que aparece como la salida de empleo en este colectivo laboral. El análisis indica que el trabajo calificado en las regiones de la capital y la frontera ha sido el que ha tenido mayor impacto sobre la estructura de los salarios en el ámbito nacional, no sólo por su mayor peso relativo, sino por presentar mayor desigualdad que el resto de las regiones y haber inducido los mayores cambios sobre la distribución total.

También la coexistencia de actividades de baja calificación en EU, como manufacturas y procesos de la maquila — que en México son etiquetadas como trabajo de alta calificación—, explicaría más bien la similitud del efecto del cambio técnico 
sesgado hacia este tipo de trabajadores. Por ello, en la agenda de investigación se requiere combinar distintas calificaciones de asalariados con una gama variada de ocupaciones, para tener una visión más completa del fenómeno.

Es importante anticiparse con la especialización del capital humano requerido y analizar en qué medida tanto el trabajo no calificado como el calificado se adaptarán al nuevo papel productivo que nos presentan los acelerados cambios técnicos de la producción. La creciente competencia de países con mayor ventaja comparativa de mano de obra que México — como el caso de China y India—, con una producción de bienes intensivos en trabajo de baja calificación, son factores que también han contribuido a que los salarios en esta materia crezcan escasamente.

\section{DeSarrollo}




\section{Bibliografía}

Acemoglu, Daron, "Technical change, inequality, and the labor market", en Journal of Political Economy, vol. XL, núm. 1, marzo, 2002, pp. 7-72.

"Directed Technical change", en NBER, Working paper núm. 8287, mayo, 2001.

Aguilar, Génaro, “Existen ricos en la economía informal? Al lado de la estación pobreza”, en El Mercado de Valores, México, agosto de 2000, pp. 48-58.

Alarcón, Diana y T. McKinley, "The Rinsing Contribution of Labor Income to Inequality in México" en North American Journal of Economics \& Finance, vol. 8, núm. 2, 1997, pp. 201-212.

Berman E, Bound J. y Griliches, Z. "Changes in the demand for skilled labor within US manufacturing industries: evidence from the anual survey of manufacturing", en NBER, Working paper núm. 4255, enero de 1993.

y Machin, S. "Implication of skillbiased technological chage: International evidence", en NBER, Working paper núm. 6166, septiembre, 1997.

Blunch, N. H., S. Canagarajah y D. Raju, "The informal Sector Revisited: A Synthesis Across Space and Time", Social Protection Discussion Paper Series, Banco Mundial, núm. 119, julio de 2001.

Castro, Lugo David, "Disparidad salarial urbana en México, 1992-2002." en Estudios Sociales, núm. 29, vol. XV, enero-junio, 2007, pp. 117-153.

Comisión Nacional de los Salarios Mínimos, Información estadística de los salarios mínimos, www.conasami.org.mx.

Davis, D. R. "Trade liberalization and income distribution", en NBER, Working papers, núm. 5693, 1996.

Dunne, T, Foster L, Haltiwanger J y Troske K, "Wage and productivity dispersion in US manufacturing: The role of computer investment", en $N B E R$, Working paper núm. 7465, enero, 2000.

Esquivel, G. y J. A. Rodríguez-López, "Technology, trade, and wage inequality in Mexico before and after NAFTA", en Journal of Development Economics, núm. 72(2), diciembre de 2003, pp. 543-565.

Hamermesh, D. S. y Grant, J. H., "Econometric Studies of Labor-Labor Substitution and their Implications for Policy", en Journal of Human Resources, núm. 14, 1979, pp. 518-542.

Hanson, Gordon, "What has happened to wages in México since NAFTA? Implications for hemispheric free trade", NBER, Working paper, núm. 9563, 2003.

y A. Harrison, "Trade liberalization and wage inequality in Mexico", en Industrial and Labor Relations Review, vol. 52 , núm 2, 1999, pp. 271-88.

Heckman, James, "Sample selection bias as a specification error", Econometrica, vol. 47(1), 1979, pp. 153-61.

Heckman, James y Guilherme Sedlacek, "Heterogeneity, aggregation and market wage functions: an empirical model of selfselection in the labor market", en Journal of Political Economy, núm. 93, 1985, pp. 1077-125.

Huesca Reynoso, Luis, "Análisis del Capital Humano y la Informalidad en el Mercado de Trabajo Mexicano", en Cuadernos del Trabajo, IX Premio Nacional a la Investigación Laboral 2006, núm. 30, Secretaría del Trabajo y Previsión Social, México, 2008a, pp. 1-132.

, "Exploración microeconómica regional del perfil de los perceptores de las remesas en México", en Remesas y desarrollo económico en México, Universidad Michoacana de San Nicolás de Hidalgo, UCLA y El Colegio de Tlaxcala, enero, 2008b, pp. 205-227.

INEGI, Encuesta Nacional de Empleo Urbano, Bases de datos años en CD-ROM 2000 y 2004.

Jenkins, Stephen y Phillipe Van Kerm, "Accounting for Income Distribution Trends: A Density Function Decomposition Approach" IZA-Discussion Paper Series, núm. 1141, mayo, 2004.

Kakwani, Nanak, "Welfare ranking of income distributions", Advance in Econometrics, vol. 3, 1984, pp. 191-213.

Kanbur, Ravi y Nora Lustig, "Why is Inequality Back on the Agenda?", en Conferencia Annual del Banco Mundial sobre Desarrollo Económico, mimeo, Banco Mundial, Washington, abril, 1999, pp. 28-30.

Katz, L. F y Murphy, K.M., "Change in relative wages, 1963-1987: supply and demand 
factors", en $N B E R$, Working paper núm. 3927, 1991.

Lambert, Peter, "Lorenz curves and welfare comparissons", en Distribution and Redistribution of Income, $3^{\text {ra }}$ edición, Manchester University Press, 2001, pp. 45-49.

y Xavier Ramos, "Welfare Comparissons: Sequential Procedures for Heterogeneous Populations", Economica, vol. 69, núm. 276, 2002, pp. 549-62.

López-Acevedo, Gladys, "Mexico: Evolution of earnings inequality and rates of returns to education (1988-2002)", en Estudios Económicos, vol. 19, núm. 2, diciembre de 2005, pp. 211-284.

Maloney, William, "Distortion and Protection in the Mexican Labor Market." Working Paper, núm. 138, Banco Mundial, Center for Research on Economic Development and Policy Reform, 2002.

, "Does informality imply segmentation in urban labor markets? Evidence from sectoral transitions in Mexico", en The World Bank Economic Review, vol. 13, núm. 2, 1999, pp. 275-302.

Martin, G., "Employment and unemployment in Mexico in the 1990s", Monthly Labor Review, november 2000, pp. 3-18.

Meza González, Liliana, "Apertura comercial y cambio tecnológico. Efectos en el mercado laboral mexicano", en El Trimestre Económico, vol. LXX, núm. 279, julio-septiembre, 2003, pp. 457-505.

, "Wage inequality and the gender wage gap in México", en Economía mexicana, Nueva época, vol. X, núm. 2, abriljunio, 2001, pp.291-323.

Oliver Alonso, Josep, Josep Luis, RaymondBara y Héctor Sala Lorda, "Necesidad de formación en el mercado de trabajo espa- ñol: composición del empleo y estructura productiva", Documento de trabajo núm. 01.07, Barcelona, Departamento de Economía aplicada, Universidad Autónoma de Barcelona, 2001.

Ramírez Cruz, María Delfina, "El empleo y la calificación de la mano de obra en México", en Comercio exterior, noviembre, 2000, pp.968-983.

"Desigualdad salarial y desplazamientos en la demanda calificada en México, 1993-1999", en El Trimestre Económico, vol. LXXI(3), núm. 283, julio-septiembre, 2004, pp. 625-680.

Sandoval, Sergio Alfonso, "Políticas de selección, contratación y entrenamiento de personal: buscando versatilidad, flexibilidad y afinidad cultural", en Hibridación, Modernización Reflexiva y Procesos Culturales en la Planta Ford Hermosillo, Plaza y Valdés, 2003, pp. 238-246.

Silverman, Bernard, Density estimation for statistics and data analysis, Chapman and Hall, Londres, 1986.

Steiner, Viktor y Robert Mohr, "Industrial chance, stability of relative earnings, and substitution of unskilled labor in West Germany", Discussion paper, ZEW Mannheim, núm. 98-22, julio 1998.

Stolper, W, y Paul Samuelson, "Protection and Real Wages", en Review of Economic Studies, vol. 9, núm. 1, 1941, pp. 51-68.

Tan H., y G. Batra, "Technology and Firm Size Wage Differentials in Colombia, Mexico and Taiwan (China)", The World Bank Economic Review, vol. 11, núm. 1, 1997, pp. 59-83.

Van-Kerm, Phillipe, "Adaptive kernel density estimation", en Stata Journal, vol. 3, núm. 2, 2003, pp. 148-56. 